\title{
Research Paper: Efficacy of Communication Skills Training in Marital Disturbance
}

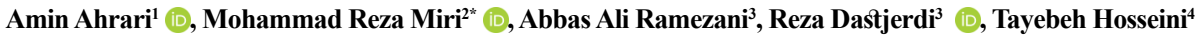 \\ 1. Student Research Committee, Birjand University of Medical Sciences, Birjand, Iran. \\ 2. Social Determinants of Health Research Center, Birjand University of Medical Sciences, Birjand, Iran. \\ 3. Department of Epidemiology and Biostatistics, School of Health, Birjand University of Medical Sciences, Birjand, Iran \\ 4. Department of Clinical Psychology, Faculty of Educational Scinces and Psychology, University of Birjand, Birjand, Iran.
}

\begin{tabular}{|l|l|}
\hline $\begin{array}{c}\text { Use vour devic to scan } \\
\text { and read thearticle online }\end{array}$ \\
Disturbance. Journal of Research \& Health. 2020; 10(6):351-358. http://dx.doi.org/10.32598/JRH.10.6. 1547.2 \\
doi http://dx.doi.org/10.32598/JRH.10.6.1547.2
\end{tabular}

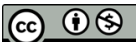

Article info:

Received: 19 Jul 2018

Accepted: 24 Nov 2019

Publish: 01 Nov 2020

\section{Keywords:}

Marital disturbance,

Communication skills, Training :

\section{A B STRACT}

Background: Marital disturbance widely impact the quality of marriage in couples. Besides, the lack of communication skills among couples is considered as one of the most significant personal factors influencing marriage distress. Therefore, this research aimed to determine the impact of communication skills training on marital disturbance.

Methods: In this interventional study, the target population was all couples residing in the marginal regions of Birjand City, in 2016. Sixty couples $(\mathrm{N}=120)$ were randomly selected and assigned into two groups of intervention (30 couples) and control (30 couples). The data collection instrument consisted of two sections of private information and the Pines couple burnout measure.

Results: Educational intervention was conducted for the intervention group in six sessions of 120 minutes. The questionnaire was completed before and three months after the intervention, in both groups. Then, the obtained data were analyzed using the chi-squared test, independent t-test, and paired t-test, considering the significant level of 0.05 , in SPSS V. 18. The Mean \pm SD age was $32.27 \pm 6.24$ years and $34.85 \pm 5.74$ years in the intervention and control groups, respectively. Also, the Mean \pm SD marriage life of couples was $7.33 \pm 5.29$ years and $9.57 \pm 5.73$ years in the intervention and control groups, respectively.

Conclusion: The mean of marital disturbance modifications, marital distress, and physical and emotional loss significantly differed between the intervention and control groups $(\mathrm{P}<0.05)$. Communication skills training can significantly reduce marital distress and its dimensions, including physical, emotional, and mental retardation, in couples living in the suburb.

\footnotetext{
* Corresponding Author:

Mohammad Reza Miri, PhD.

Address: Social Determinants of Health Research Center, Birjand University of Medical Sciences, Birjand, Iran.

Phone: +98 (915) 1615468

E-mail:miri_moh2516@yahoo.com
} 


\section{Introduction}

arital disruption along with emotional requirements is a state of physi$\mathbf{M}$ cal, emotional, and mental exhaustion, which happens in long-term conflicts. Marital disorder results from the chronic absence of fitness between expectations and reality [1]. Marital disruption is caused by a complex of unrealistic expectations, irrational thoughts, and the issues of life, and leads to the collapse of the relationship, within its most serious form [2]. Physical, emotional, and psychological symptoms manifest the marriage disturbance [3]. In reality, physical or emotional fatigue is a chronic fatigue disorder that does not resolve through sleep. In the instances of emotional fatigue, the patients always believe that they are mentally annihilated and are always distressed. Psychological fatigue arising from disruption is expressed by the reduced self-esteem and an adverse attitude towards relationships, particularly spousal relationships [4]. Research by family professionals shows that marriage disruption has risen in incidence; today, $50 \%$ of married couples face marital disruption [5].

Divorce is one of the most significant effects of marital disruption [6]. According to the National Organization for Civil Registration of Iran, the number of formal divorces had a drastic and alarming trend over five years; it raised from 142841 instances by the end of 2011 to 163 765 instances by the end of 2015 . Also, the marriage to divorce ratio has greatly changed over the same period. In 2011, this ratio was 6 to 1 across the nation, meaning that one divorce was recorded for every six licensed marriages. However, this ratio was 4 to 2 at the end of 2015 , meaning that two divorces were recorded for every four licensed marriages [7].

The formal divorce statistics do not fully represent the level of marital life failure, because a bigger percentage of emotional divorces still exists. Emotional divorces can be ascribed to a double rate of divorce [6]. Most weddings start with love, but over time some conflicts make the marriage a shared life without feeling and love. In these cases, couples continue to live together and refuse the official separation, because of kids or other reasons [8].

The absence of communication skills among couples is one of the most significant variables in the incidence of marriage disturbance [9-12]. One of the best ways to build a matching marital relationship is to inform couples about the communication skills to assist them in future disputes [11]. Relationship abilities are acquirable behaviors needed for efficient martial life, and include awareness-raising and creating the right environment to develop such behaviors [13]. These skills include a complex of skills that match individuals and create positive and useful habits. These skills allow people to correctly perform their parts in society, without harming themselves or others [14].

Several studies have examined the role and impact of communication skills training in decreasing marital disruption [9-11, 15, 16]. However, some studies have noted that martial skills education was not efficient in couples [17]. Therefore, it seems necessary to determine the function of communication skills education in the marital disruption of couples. Furthermore, the marital disruption is of excellent significance, impacts the marriage relationships of couples, and has several implications. Besides, the studies concerning marital disturbances have been only conducted on women. So, this research aimed to determine the impact of communication skills training on marital disturbance.

\section{Methods}

The target population of this interventional study included all the couples residing in the marginal regions of Birjand City, in 2016. The sample size was defined considering the standard deviation of 9.79 and 7.62 before and after the procedure, respectively, based on the results of Bashir et al. [9]. Also, the epsilon value was regarded to be 8 out of 60 couples. Therefore, 30 couples were chosen as the intervention group and 30 couples were chosen as a control group, using a random sampling method among the couples residing in Birjand neighborhoods.

First, from the eight northern and southern suburbs of Birjand ( 2 centers from the north and 2 centers from the south), four extensive healthcare centers were chosen using nonrandom sampling. Based on the population of each center, couples with at least one year of marriage duration who met the inclusion criteria were selected, according to the list of households in the SEEB system. Then, using systematic random sampling, 200 couples (400 individuals) were chosen from four centers to complete the study questionnaire. The selected couples were invited to the briefing session, and the aim of the project was clarified to them; it was stressed that the participants' information is confidential. Then, the couples received written permission and were trained to correctly complete the questionnaire. After finishing the questionnaire, the participants were evaluated to determine the degree of marriage disruption between couples. Then, using an easy nonrandom method, 60 couples with a marriage 
Table 1. Agenda of communication skills training in the intervention group

\begin{tabular}{cl}
\hline Sessions & \multicolumn{1}{c}{ Descriptions } \\
\hline 1 & $\begin{array}{l}\text { Introducing the rules and objectives of the study and the number of sessions, defining communication, educating } \\
\text { how to communicate, and providing an assignment. }\end{array}$ \\
Reviewing the task of the previous session, teaching verbal and nonverbal skills, modeling the skill for the members \\
and training during the session, providing an assignment.
\end{tabular}

MPA

disruption of level 3 or greater were chosen from four centers to perform the instructional intervention. They were randomly assigned into the two groups of intervention ( 30 couples) and control ( 30 couples). The inclusion criteria were being married for at least one year, having a marital disturbance rate of 3 or above, not living with relatives in the same home, not having depression, and not taking any medication for depression. Furthermore, the exclusion criteria were the lack of at least two meetings and more, couples' unwillingness to continue participating in the project, and divorce during the project.

A demographic information questionnaire and the Couple Burnout Measure (CBM) were included in the data collection instrument. The CBM scale is a selfmeasuring instrument that was initially implemented by Piens to assess the degree of marital disruption between couples. This scale comprises of three primary parts: physical burnout (fatigue, weakness, and sleep disorders), emotional burnout (depression, frustration, and feeling trapped), and mental burnout (worthiness, frustration, and anger toward spouse). The CBM scale includes 21 questions, 17 of which are about adverse issues, such as fatigue, pain, and worthlessness, also, four questions contain positive sentences, such as happiness and energy. The questions are scored on a 7-point scale from "never" to "always", graded from 1 to 7. The CBM examines the frequency of the occurrences of the items in the marital relationship of respondents.

The scores achieved for items 1, 2, 4, 5, 7, 8, 9, 10, 11, $12,13,14,15,16,17,18$, and 21 were summed up to determine the degree of burnout in the first phase, also, the scores of the items 3, 6, 19 and 20 were added in the second phase. Then, in the third phase, the second phase results were decreased by 32 . In the fourth phase, the scores from the first and third phases were summed up, and in the final phase, the score from the fourth phase was divided by 21 to calculate the burnout rate. A score of 2 and below stands for a healthy partnership, a score of 3 shows burnout line, a score of 4 displays burnout state, a score of 5 displays burnout crisis, and a score of over 5 indicates the urgent need for assistance [11, 18-22].

The validity evaluation of the CBM showed an internal consistency range of 0.84 . to 0.90 between the factors [ 19 , 20, 22]. Furthermore, Bashir obtained the reliability coefficient of 0.79 , using the Cronbach alpha; this value was 0.91 in Basharpoor et al.'s research $[9,18]$. In the next phase, an MSc in Clinical Psychology and an MSc in Health Education and Health Promotion performed training for the intervention group, in six instructional sessions (2 sessions per week, 120 minutes each). Material training was provided based on the book on marriage communication skills training (Speaking and Listening) [23] (Table 1).

Ultimately, the Kolmogorov-Smirnov test was used to evaluate the normal distribution of the data. Then, the data analysis was carried out using the chi-squared, autonomous t-test, and paired t-test. All the analyses were performed at the significance level of 0.05, using SPSS V. 18 .

\section{Results}

The Mean \pm SD age of the participants in the intervention and control groups was $32.27 \pm 6.24$ years and $34.85 \pm 5.74$ years, respectively. Also, the Mean \pm SD marriage life of couples in the intervention and control groups was $7.33 \pm 5.29$ years and $9.57 \pm 5.70$ years, respectively. Furthermore, the Mean \pm SD number of the couples' kids was $1.53 \pm 1.29$ and $1.90 \pm 0.95$ in the intervention and control groups, respectively. A high school degree was the most common level of education in couples, also, most of the studied wives were housekeepers. 
Table 2. Comparison of the demographic information of the participants between the intervention and control groups

\begin{tabular}{|c|c|c|c|c|}
\hline & \multirow{2}{*}{ Variables } & \multicolumn{2}{|c|}{ No. (\%) } & \multirow{2}{*}{$\begin{array}{c}\text { Result of Chi-square and } \\
\text { Fisher Tests }\end{array}$} \\
\hline & & Intervention Group & Control Group & \\
\hline \multirow{7}{*}{ Education level } & No education & $2(50)$ & $2(50)$ & \multirow{7}{*}{$P=0.952$} \\
\hline & Reading and writing & $1(33.3)$ & $2(66.7)$ & \\
\hline & Elementary school & $10(62.5)$ & $6(37.5)$ & \\
\hline & & & & \\
\hline & Middle school & $11(45.8)$ & $13(54.2)$ & \\
\hline & High school degree & $18(46.1)$ & $21(53.9)$ & \\
\hline & University degree & $18(52.1)$ & $16(47.9)$ & \\
\hline \multirow{5}{*}{ Occupation } & Employee & $8(38.1)$ & $13(61.9)$ & \multirow{5}{*}{$P=0.496$} \\
\hline & Self-employed & $24(54.1)$ & $23(48.9)$ & \\
\hline & & & & \\
\hline & Not employed & $1(100)$ & $0(0)$ & \\
\hline & Housekeeper & 27 (52.9) & $24(47.1)$ & \\
\hline \multirow{3}{*}{ Way of meeting } & Through family or friends & $48(48)$ & $52(52)$ & \multirow{3}{*}{$P=0.327$} \\
\hline & & & & \\
\hline & We met ourselves & $12(60)$ & $8(40)$ & \\
\hline \multirow{3}{*}{ Fertility status } & Fertile & $56(49.1)$ & $58(50.9)$ & \multirow{3}{*}{$P=0.554$} \\
\hline & Infertile & $2(50)$ & $2(50)$ & \\
\hline & Unknown & $2(100)$ & $0(0)$ & \\
\hline
\end{tabular}

MRA

The intervention and control groups did not significantly differ in terms of age, the level of schooling, occupation, the number of kids, the years of cohabitation, fertility status, and meeting technique ( $\mathrm{P}>0.05)$ (Tables 2 and 3 ).

The comparison of the average marital disturbance rating and its pre-intervention size showed a substantial distinction in marital disruption $(\mathrm{P}=0.027)$, physical burnout $(\mathrm{P}=0.005)$, and mental burnout $(\mathrm{P}=0.037)$, between the two groups. However, there was no important distinction between the average marital disturbance results $(\mathrm{P}=0.02)$ and mental burnout $(\mathrm{P}=0.339)$. The comparison of average marital disturbance results and their values after-action showed that the average marital disturbance score and its size were not substantially distinct between the intervention and control groups $(\mathrm{P}>0.05)$. Furthermore, the average marital disturbance rating and its sizes considerably differed from those acquired three months after the instructional intervention $(\mathrm{P}<0.05)$; these values improved after the intervention (Table 4).

The comparison of average marital disturbance score alterations, the degree of marital disruption, and physi- cal and emotional burnout dimensions showed that these factors considerably differed between the intervention and control groups $(\mathrm{P}<0.05)$ (Table 5).

\section{Discussion}

The findings of this research showed that communication skills training significantly decrease the average rate of marital disruption and its dimensions, including physical, mental, and emotional burnout in the intervention group, compared with the control group. In other words, the average decrease of the marital disturbance score and its dimensions were statistically significant in the intervention group, but this decrease was not significant in the control group.

Karkhaneh et al. explored the efficacy of communication skills training (based on TA) in the decreasing of marital disruption in the couples of Kermanshah City. Their findings showed that communication skills training efficiently decreased the marital disruption between the couples [16]. Also, Sajjadi and Roshan assessed the 
Table 3. Comparison of the average demographic factors between the intervention and control groups

\begin{tabular}{|c|c|c|c|}
\hline \multirow{2}{*}{ Variables } & \multicolumn{2}{|c|}{ Mean $\pm S D$} & \multirow{2}{*}{ Result of Statistical Test } \\
\hline & Intervention & Control & \\
\hline Age $(y)$ & $32.27 \pm 6.24$ & $34.8 \pm 5.74$ & $\mathrm{P}=0.02$ \\
\hline Number of children & $1.53 \pm 1.29$ & $1.90 \pm 0.95$ & $P=0.080$ \\
\hline Years of marriage & $7.40 \pm 5.25$ & $9.57 \pm 5.70$ & $P=0.032$ \\
\hline Years of residence & $3.93 \pm 2.58$ & $4.77 \pm 4.24$ & $P=0.196$ \\
\hline
\end{tabular}

MRA

Table 4. Comparison of the average marital disturbance rating and its size in the intervention and control groups

\begin{tabular}{|c|c|c|c|c|}
\hline \multirow{2}{*}{ Scales } & \multirow{2}{*}{ Groups } & \multicolumn{2}{|c|}{ Mean士SD } & \multirow{2}{*}{ Result of Statistical Test } \\
\hline & & Before Intervention & After Intervention & \\
\hline \multirow{3}{*}{ Marital disturbance } & Intervention & $69.90 \pm 18.780$ & $61.27 \pm 17.655$ & $P<0.001$ \\
\hline & Control & $63.13 \pm 14.074$ & $60.83 \pm 14.953$ & $P=0.183$ \\
\hline & Independent t-test result & $P=0.027$ & $P=0.885$ & \\
\hline \multirow{3}{*}{$\begin{array}{l}\text { Level of marital distur- } \\
\text { bance }\end{array}$} & Intervention & $2.75 \pm 0.968$ & $2.38 \pm 0.904$ & $P<0.001$ \\
\hline & Control & $2.50 \pm 0.770$ & $2.40 \pm 0.807$ & $P=0.347$ \\
\hline & Independent t-test result & $P=0.120$ & $P=0.915$ & \\
\hline \multirow{3}{*}{ Physical burnout } & Intervention & $22.68 \pm 6.259$ & $19.22 \pm 5.935$ & $P<0.001$ \\
\hline & Control & $19.53 \pm 5.870$ & $19.03 \pm 5.969$ & $P=0.575$ \\
\hline & Independent t-test result & $P=0.005$ & $P=0.866$ & \\
\hline \multirow{3}{*}{ Emotional burnout } & Intervention & $22.43 \pm 5.542$ & $19.95 \pm 6.614$ & $P<0.001$ \\
\hline & Control & $20.08 \pm 5.594$ & $19.73 \pm 5.692$ & $p=0.623$ \\
\hline & Independent t-test result & $P=0.037$ & $P=0.848$ & \\
\hline \multirow{3}{*}{ Psychological burnout } & Intervention & $24.78 \pm 8.126$ & $22.10 \pm 6.927$ & $P=0.001$ \\
\hline & Control & $23.52 \pm 6.201$ & $22.07 \pm 5.544$ & $P=0.052$ \\
\hline & Independent t-test result & $P=0.339$ & $P=0.977$ & \\
\hline
\end{tabular}

MPA

efficacy of communication skills education in encouraging love behavior and decreasing marital disruption, in married females studying at the Mashhad University of Medical Sciences. They found that schooling efficiently reduced the degree of marital disruption between couples [15]. Bashir et al. performed a survey entitled "Effectiveness of communication skills education in Nehbandan Payame Noor University learners with emphasis on Islamic doctrines on mental order of joy and marriage disruption". The participants were trained on communication skills and reported that this training was efficient in decreasing marriage disruption [9]. Moreover, Navidian et al. [24], Dehghan et al. [25], Sirin and Dennis [26], and Yaghoutian et al. [11] revealed that educational interventions were efficient in decreasing marriage disruption. Soori and Goodarzy [17] carried out a survey entitled "The impact of communications enrichment education on work burnout and marriage disruption among Sanan- 
Table 5. Comparison of the average score changes of marital disturbance and its dimensions before and after the educational intervention

\begin{tabular}{cccc}
\hline \multirow{2}{*}{ Scale } & \multicolumn{2}{c}{ Mean \pm SD } & P-value of Independent t-test \\
\cline { 2 - 4 } & Before Intervention & After Intervention & 0.005 \\
\hline Score of marital disturbance & $10.764 \pm-8.63$ & $13.220 \pm-2.30$ & 0.05 \\
Level of marital disturbance & $0.712 \pm-0.37$ & $0.817 \pm-0.5$ & 0.009 \\
\hline Physical burnout & $5.277 \pm-3.47$ & $6.861 \pm-0.50$ & 0.023 \\
\hline Emotional burnout & $4.601 \pm-2.48$ & $5.486 \pm-0.35$ & 0.232 \\
\hline Psychological burnout & $5.592 \pm-2.68$ & $5.664 \pm-1.45$ & \\
\hline
\end{tabular}

daj Tohid Hospital nurses". Their findings showed that the education programs of communication enrichment did not reduce burnout and marital disruption in nurses. Most of these studies have addressed females and overlooked men's involvement. Thus, women's education alone does not seem sufficient, and it is better to concentrate on educational interventions for both spouses.

The findings of this research showed that communication skills training decreased physical burnout in couples. When individuals feel careful, worthy, and affection, their health is maintained against the anxieties of life [16]. The quality of marriage life is the consequence of the views, ideas, behaviors, actions, past choices, and performances of the couples. Educating and applying communication skills in couples helps to enhance hope and happiness in their relationships and encourage them to restore their previous relationships with their spouses. This will reduce marriage disruption and physical burnout [27]. The lack of an appropriate and joyful marital relationship between couples contributes to stress and anxiety, which in turn makes the couples susceptible to physical issues, such as chronic headaches, boredom, and lethargy. Communication skills training in couples assists them to decrease tension by using enhanced verbal skills, active listening, and problem-solving abilities. Also, the training will result in less physical burnout and marital disruption.

Findings from this research showed that communication skills education decreased emotional burnout in couples. The accumulation of small discords will turn to future warning signs, including disputes and anger. Anger arises with a great deal of psychological stress and consumes a great deal of energy [27]. Furthermore, couples' failure to solve the problems, even the tiny conflicts and disagreements, impose extra emotional stress on them. Educating listening abilities and emotional expres- sion provides emotional support for couples. The ability to hear and pay attention to the spouse's speech makes it possible to understand the spouse emotionally and intellectually [16]. Communication skills education enhances cognitive skills in couples. Also, the alternation of couples' emotions and actions change their approaches. Ultimately, these modifications enhance intimacy and marital happiness and reduce emotional burnout among couples [27]. If couples inappropriately solve their problems (for instance, repeating silence in marital disputes), they will experience depression and frustration, emptiness and shallowness, and a sense of confusion and disorder. The training of communication skills enables couples to suitably resolve their marital disputes, enhances joy and happiness in their relationships, reduces emotional problems that may result in emotional burnout, and decreases marital disruption between couples.

Furthermore, the findings showed that communication skills education decreases mental burnout in couples. The existence of some prevalent misunderstandings can distort people's knowledge of reality and develop unpleasant behaviors. Improving communication skills increases positive self-esteem and reduces negativity, and eventually leads to lower marriage disturbance among couples [27]. Cognitive mistakes occur between couples when they are unable to properly use the verbal and active listening abilities and properly interpret each other's phrases. Educating communication skills, including talking and listening abilities, enables couples' adverse attitudes towards one another to reduce mental burnout and marital disruption.

The limitations of this research include the restricted sampling area, which limits the generalizability of the results to other larger areas. Also, we were unable to monitor the accuracy of the answered questions. However, this study included some strengths, such as conducting 
educational intervention on couples, including a control group, and evaluating the intervention's impact after three months. Because of the significance of the problem, it is proposed to design and implement health education programs in other areas (with distinct cultures).

\section{Conclusion}

At all times, integrated instructional planning based on the requirements of the public is the most significant instrument for problem avoidance. Since education is one of the primary pillars of health care, it can be helped by offering principles and applying training to at-risk couples, particularly in delicate fields, such as urban suburbs, to create an efficient connection between them. This connection can assist them to develop and thrive. This approach not only decreases the tensions and frustrations during marriage life but also prevents the development or continuation of malicious and negative feelings. Eventually, educating couples in communication skills can decrease marriage disruption.

\section{Ethical Considerations}

\section{Compliance with ethical guidelines}

This study was approved by the Ethics Committee of the University of University of Medical Sciences of Birjand (Ethics Code: IR.BUMS.REC.1395.263). Also, all ethical principles are considered in this article. The participants were informed of the purpose of the research and its implementation stages.

\section{Funding}

This research did not receive any grant from funding agencies in the public, commercial, or non-profit sectors.

\section{Authors' contributions}

All authors equally contributed to preparing this article.

\section{Conflict of interest}

The authors declared no conflict of interests.

\section{Acknowledgments}

The authors would like to thank the Deputy of Research and Technology of the University of Medical Sciences of Birjand, as well as the Extensive Health Centers of Mehrshahr and Masumyeh in Birjand and the Health Centers of Kazemiyeh and Zafar in Birjand for their cooperation in data collection.

\section{References}

[1] Karim Nejad L, Jahanian S, Farghadani A. [Comparing strategies of cognitive emotion regulation and gender roles among couples with high and low couple burnout (Persian)]. Int J Behav Sci. 2014; 5(18):161-83. https://www.sid.ir/fa/journal/ ViewPaper.aspx?ID=253659

[2] Bakhtiyarpur S, Ameri Z. [The relationship between specific attachment to his wife and irrational beliefs with distraction, teachers married couple in Ahvaz (Persian)]. J Soc Psychol. 2009; 4(10):53-70. https://www.sid.ir/fa/journal/ViewPaper.aspx?id=124196

[3] Adib Rad N, Adib Rad M. [Study of the relationship of communication believes and marital disenchantment and its comparison with divorce seeking women and common life seeking women (Persian)]. J Counsel Res. 2005; 4(13):99-110. https://www.sid.ir/Fa/Journal/ViewPaper.aspx?id=26940

[4] Lee TY, Sun GH, Chao SC. The effect of an infertility diagnosis on the distress, marital and sexual satisfaction between husbands and wives in Taiwan. Hum Reprod. 2001; 16(8):1762-7. [DOI:10.1093/humrep/16.8.1762] [PMID]

[5] Pines AM. Couple burnout: Causes and cures Routledge. New York: Routledge; 1996. https://www.worldcat.org/title/couple-burnout-causes-and-cures/oclc/877244854?refere $\mathrm{r}=$ di\&ht=edition

[6] Bastani S, Golzari M, Rowshani S. [Emotional divorce and strategies to face it (Persian)]. Journal of Family Research. 2011; 7(2):241-57. http://jfr.sbu.ac.ir/article/view/137

[7] Sabteahval. Office of Statistics and Demographic Information and Immigration [Internet]. 2011 [Updated 21 June 2020]. Available from: https://www.sabteahval.ir/avej/Page.aspx $? \mathrm{mId}=49826 \& \mathrm{ID}=3257 \&$ Page $=$ Magazines $/$ SquareshowMag azine

[8] Hajiani E Haghighatian M, Keshavarz H, Yazdani A. [An analysis of quality of life among emotional divorced women, Shahrekord: A case study (Persian)]. Soc Cult Strat J. 2013; 2(6):159-85. https://www.sid.ir/En/Journal/ViewPaper. aspx? $\mathrm{ID}=375595$

[9] Bashir A. [The effectiveness of communication skills training with emphasis on religious teachings on atmospheric cognitive emotion regulation and marital boredom Payam Noor university students Nehbandan (Persian)] [MA. thesis]. Khorasan: Islamic Azad University of Birjand; 2016.

[10] Attari YA, Hosseinpour M, Rahnavard S. [Effectiveness of communication skills (couple communication program) upon marital dissatisfaction (Persian)]. Andisheh va Raftar 2010; 4(14):25-34. https://www.sid.ir/fa/journal/ViewPaper.aspx?id $=127404$

[11] Yaghotian M, Soleymanian A, Bakhshi M. [Effectiveness of enriching relationship on decrease of marital burnout of mothers of children with visual disabilities (Persian)]. J Excep Edu. 2015; 15:28-34. http://exceptionaleducation.ir/article1-574-fa.html

[12] Molodi A. The relationship between communication skills and marital burnout with marital commitment in working women and housewives. Int J Psychol Behav Res. 2015; 4(3):285-9. https://www.sid.ir/en/journal/ViewPaper. aspx?ID=557352 
[13] Herzon J. What are life skills education. Washington, DC: Office Juvenile Justiceand Delinguecy Prevrntion; 2002.

[14] Ahmadi MS. [Effectiveness of training communication skillson self-regulated learning of male high school students in Zanjan City (Persian)]. Knowl Res Appl Psychol. 2014; 15(1):113-20 http://journals.iau.ir/article_533911_8f1f86aa8bfba614eb3da25 c047536fb.pdf

[15] Sajadi S, Roshan R. [Effectiveness of communication skills on attitude toward love and marital burnout (Persian)]. J Counsel Res. 2015; 14(53):91-111. http://irancounseling.ir/journal/article-1-122-fa.html

[16] Karkhaneh M, Karkhaneh M. [The effectivness of the training of communication skills in reducing marital burnout among the couples of Kermanshah (Persian)]. The $2^{\text {nd }}$ National Conference and the First International Conference on Modern Research in the Humanities. Tehran; 2015. https://civilica.com/ doc/390687/

[17] Soori Kableh S, Goudarzi M. The effect of communication enrichment training on reduction of occupational burnout and marital boredom among nurses of Tohid Hospital in Sanandaj. Int J Hum Cult Stud (IJHCS). 2016:1393-400. http:/ / www.ijhcs. com/index.php/ijhcs/article/viewFile/2119/1901

[18] Basharpoor S, Mohammadi N, Sadeghivelni Z. [The role of emotional control and relational beliefs in predicting couple burnout (Persian)]. Soc Psychol Res. 2015; 5(17):52-64. http:// www.magiran.com/view.asp?Type $=$ pdf\&ID $=1450304 \& l=e n$

[19] Behzadpoor S, Motahhari ZS, Vakili M, Sohrabi F. [The effect of resilience training on increasing psychological well-being of infertile women (Persian)]. J Ilam Uni Med Sci (JIUMS). 2015 23(5):131-42. http:// sjimu.medilam.ac.ir/article-1-2537-en.html

[20] Nikoubakht N, Karimi U, Bahrami H. [Couple burnout among fertilized and unfertilized women referred to Valieasr Reproductive Center, Tehran (Persian)]. Iran J Epidemiol (IRJE). 2011; 7(1):32-7. http://irje.tums.ac.ir/browse.php?a_code=A10-25-59\&slc_lang=en\&sid $=1$

[21] Babaei Givi R, Nazari A, Mohsenzadeh F. [Comparison of psychological well-being and marital burnout and their dimensions among employed and unemployed woman (Persian)]. Q J Women and Society. 2016; 7(25):163-80. http://jzvj.miau.ac.ir/ article_1843_en.html

[22] Asadi E, Mansour L, Khodabakhshi Koolaei A, Fathabadi J. The relationship between couple burnout, sexual assertiveness, and sexual dysfunctional beliefs in women with diabetic husbands and comparing them with women with non-diabetic husbands. J Fam Res. 2013; 9(3):311-24. http://jfr.sbu.ac.ir/article/ view/10147

[23] Miller S, Miller P, Natali AV, Vakman DB. Teaching marital skills (speaking and listening to each other). [Bahari F, Persian trans]. Tehran: Roshd; 2016.

[24] Navidian A, Rezaee N, Baniasadi F, Shakiba M. Effect of a couples' relationship enrichment program on the couple burnout from the perspective of spouses of patients with Multiple Sclerosis. Issues Ment Health Nurs. 2017; 38(9):756-62. [DOI:10.1 080/01612840.2017.1294221] [PMID]

[25] Dehghan F, Piri Kamrani M, Goli R, Rahmani H. [The impact of life skills training on marital satisfaction, marital dissatisfaction and mental health of veteran's wife (Persian)]. Q J Woman and Society. 2017; 7(28):1-12. http://jzvj.miau.ac.ir/article_2263. $\mathrm{html}$
[26] Sirin HD, Deniz ME. The effect of the family training program on married women's couple-burnout levels. Educ Sci Theory and Pract. 2016; 16(5):1563-85. [DOI:10.12738/ estp.2016.5.2781]

[27] Pir Falak M, Soodani M, Shafi Abadi A. [The effectiveness of cognitive-behavioral group couples therapy (GCBCT) on reducing marital distress (Persian)]. Fam Couns Psychother. 2014; 4(2):247-69. http:/ / fcp.uok.ac.ir/article_9670.html 